\title{
Comparative efficacy of combination bronchodilator therapies in COPD: a network meta-analysis
}

This article was published in the following Dove Press journal: International Journal of COPD

9 September 2015

Number of times this article has been viewed

\author{
Eline L Huisman' \\ Sarah M Cockle 2 \\ Afisi S Ismaila ${ }^{3,4}$ \\ Andreas Karabis' \\ Yogesh Suresh Punekar ${ }^{2}$ \\ 'Mapi Group, Real World Strategy \\ and Analytics and Strategic Market \\ Access, Houten, the Netherlands; \\ ${ }^{2}$ Value Evidence and Outcomes, \\ GlaxoSmithKline, Uxbridge, UK; \\ ${ }^{3}$ Value Evidence and Outcomes, \\ GlaxoSmithKline R\&D, Research \\ Triangle Park, NC, USA; ${ }^{4}$ Clinical \\ Epidemiology and Biostatistics, \\ McMaster University, Hamilton, \\ ON, Canada
}

Correspondence: Yogesh Suresh Punekar Value Evidence and Outcomes, GlaxoSmithKline, Stockley Park, Uxbridge UBI I IBT, UK

Tel +44208990 4786

Fax +442089903505

Email yogesh.q.punekar@gsk.com
Background: Several new fixed-dose combination bronchodilators have been recently launched, and assessing their efficacy relative to each other, and with open dual combinations is desirable. This network meta-analysis (NMA) assessed the efficacy of umeclidinium and vilanterol (UMEC/VI) with that of available dual bronchodilators in single/separate inhalers.

Methods: A systematic literature review identified randomized controlled trials of $\geq 10$ weeks among chronic obstructive pulmonary disease patients ( $\geq 40$ years), assessing the efficacy of combination bronchodilators in single or separate inhalers. Comparative assessment was conducted on change from baseline in trough forced expiratory volume in 1 second $\left(\mathrm{FEV}_{1}\right)$, St George's Respiratory Questionnaire (SGRQ) total scores, transitional dyspnea index (TDI) focal scores, and rescue medication use at 12 weeks and 24 weeks using an NMA within a Bayesian framework. Results: A systematic literature review identified 77 articles of 26 trials comparing UMEC/VI, indacaterol/glycopyrronium (QVA149), formoterol plus tiotropium (TIO) $18 \mu \mathrm{g}$, salmeterol plus TIO, or indacaterol plus TIO, with TIO and placebo as common comparators at 12 weeks and approximately 24 weeks. The NMA showed that at 24 weeks, efficacy of UMEC/VI was not significantly different compared with QVA149 on trough $\mathrm{FEV}_{1}$ (14.1 mL [95\% credible interval: -14.2 , $42.3])$, SGRQ total score $(0.18$ [ $-1.28,1.63])$, TDI focal score $(-0.30[-0.73,0.13])$, and rescue medication use $(0.02[-0.27,0.32])$; compared with salmeterol plus TIO on trough $\mathrm{FEV}_{1}(67.4 \mathrm{~mL}$ $[-25.3,159.4])$, SGRQ total score $(-0.11[-1.84,1.61])$, and TDI focal score $(0.58[-0.33,1.50])$; and compared with formoterol plus TIO $18 \mu \mathrm{g}$ on SGRQ total score $(-0.68[-1.77,0.39])$. Results at week 12 were consistent with week 24 outcomes. Due to lack of availability of evidence, no comparison was made with formoterol plus TIO on $\mathrm{FEV}_{1}$ or TDI at 24 weeks.

Conclusion: UMEC/VI has comparable efficacy to other dual-bronchodilator combinations on available efficacy endpoints.

Keywords: LABA/LAMA, UMEC/VI, QVA149, fomoterol, tiotropium, glycopyrronium, indacaterol, umeclidinium

\section{Introduction}

Recommendations for COPD treatment are primarily based on the burden of symptoms, categorized using the modified Medical Research Council and COPD assessment test questionnaires, and on risks, assessed based on severity of airflow limitation and history of exacerbations. ${ }^{1}$ Studies have shown that coadministration of long-acting muscarinic antagonists (LAMAs) and long-acting $\beta_{2}$-agonists (LABAs) is more effective than treatment with either drug class alone in stable COPD as the combination offers improvement in airflow obstruction, dynamic hyperinflation, reduction in rescue medication, and a safety profile that is similar to the components..$^{2-4}$

LABA/LAMA combinations evaluated in clinical studies include open combinations of a LABA such as formoterol (FOR), salmeterol (SAL), or indacaterol (IND) 
and of a LAMA such as tiotropium (TIO), glycopyrronium (GLY), or aclidinium, and newer once-daily (OD), fixed-dose combinations such as umeclidinium and vilanterol (UMEC/ VI, Anoro ${ }^{\circledR}$ Ellipta $^{\circledR}$ ) and IND/GLY (QVA149, Ultibro ${ }^{\circledR}$ Breezhaler $\left.^{\circledR}\right)$. Studies have shown that UMEC/VI is well tolerated and offers greater improvements in lung function, health status, and dyspnea scores compared with placebo and better lung function compared with its monotherapy components and TIO. $.^{5-9} \mathrm{UMEC} / \mathrm{VI}$ administration in a single inhaler (Anoro $^{\circledR}$ Ellipta $^{\circledR}$ ) has been approved by the US Food and Drug Administration and the European Medicines Agency as a OD maintenance treatment for airflow obstruction in patients with COPD. ${ }^{10}$ The nominal dose of UMEC/VI is $62.5 / 25 \mu \mathrm{g}$ OD per the US label, whereas the actual dose delivered is $55 / 22 \mu \mathrm{g}$ mentioned in the European Union label. Similarly, several studies have evaluated the safety and efficacy of other open-combination dual bronchodilators with a variety of dosing regimens, such as FOR + TIO $(12 \mu \mathrm{g}$ metered dose $/ 10 \mu \mathrm{g}$ delivered dose twice daily (bid) $+18 \mu \mathrm{g}$ OD), SAL + TIO (50 $\mu \mathrm{g}$ bid +18 $\mu \mathrm{g}$ OD), IND + TIO $(150 \mu \mathrm{g}+18 \mu \mathrm{g}$ OD), and QVA149 (nominal dose, 110/50 $\mu \mathrm{g}$ OD; delivered dose, $85 / 43 \mu \mathrm{g}$ OD) in patients with moderateto-very severe COPD. ${ }^{11-21}$

With the recent introduction of a new class of fixed-dose combination bronchodilators (UMEC/VI and QVA149) 22,23 and several others under development, assessing their efficacy relative to each other and with open dual combinations is desirable. Therefore, this study aimed to perform a systematic literature review (SLR) and to synthesize, by means of a Bayesian network meta-analysis (NMA), the published evidence on the efficacy of the fixed combination of UMEC/VI (55/22 $\mu \mathrm{g}$ OD) with that of all available dual-bronchodilator combinations in single or separate inhalers. The relative efficacy of the treatments was assessed at 12 weeks and 24 weeks by means of difference in change from baseline (CFB) on lung function (trough forced expiratory volume in 1 second $\left[\mathrm{FEV}_{1}\right]$ ), health status (St George's Respiratory Questionnaire [SGRQ] total score), difference in transitional dyspnea index (TDI) focal score, and difference in rescue medication use.

\section{Methods}

\section{Data sources}

The study protocol was approved by GSK internal protocol review committee. Since the study was based on data extracted from published literature, it was exempt from human subjects review.

An SLR was conducted to identify randomized controlled trials (RCTs) comparing UMEC/VI with alternative LABA/
LAMA open and fixed combinations, using appropriate databases and registries from their inception up to April 16, 2014. RCTs in English language were included. A broad search strategy was employed to cover the entire range of available LABA, LAMA, or LABA/LAMA comparators. Details of the databases, selection criteria, and the search strategies are presented in Tables S1 and S2, respectively.

\section{Inclusion criteria and study selection process}

Identified abstracts were independently assessed by two reviewers as per predefined selection criteria: patient population - adult COPD patients (age $\geq 40$ years of any race and sex); interventions - UMEC/VI; comparators - LABA/ LAMA, placebo, TIO $18 \mu \mathrm{g}$ (henceforth, TIO = TIO $18 \mu \mathrm{g}$ ); outcomes $-\mathrm{FEV}_{1}$, SGRQ total scores, TDI focal scores, and rescue medication use; study design - RCTs of $\geq 10$-week duration.

Studies were included in the SLR if they compared interventions of interest in the analysis with each other or with placebo. During the SLR protocol development, it was known that three of UMEC/VI RCTs (clinical study reports provided by GlaxoSmithKline) had TIO as comparator. Due to this, we decided to include TIO as one of the comparators in the selection criteria. Because both $\mathrm{TIO}$ and placebo were selected as potential common comparators, studies comparing TIO with placebo were also of interest to strengthen the network.

\section{Data abstraction and quality assessment}

For studies that met the selection criteria, the following information was extracted: study design, patient characteristics, types of intervention and comparators, outcomes of interest, and patient withdrawals with reasons for withdrawal.

For each trial, the mean difference in CFB between the arms of interest (or least square mean) and the 95\% confidence interval $(95 \% \mathrm{CI})$, standard error (SE), or standard deviation (SD) were abstracted, where available. If not reported, the difference in $\mathrm{CFB}$ was calculated based on the CFB (or least square mean) per treatment arm. If not reported, the SE was imputed using the uncertainty of other trials in the network. A checklist for RCTs based on the guidance by the Institute for Quality and Efficiency in Health Care was used for risk of bias assessment. ${ }^{24}$

An effect modifier is a study or patient characteristic that influences the treatment effect. Because of the randomization process, potential effect modifiers are expectedly balanced between treatment arms within an RCT. However, an NMA involves different trials comparing different interventions. Therefore, the distribution of effect modifiers not only varies 
across studies for a particular comparison (heterogeneity) but also between comparisons (inconsistency). Although slight variations in patient characteristics across studies are always expected, an NMA is only valid when no imbalances exist in effect modifiers across comparisons. To reduce the risk of biased outcomes in the NMA, data from only studies that are similar with respect to patient populations and study designs should be compared. ${ }^{25,26}$

The similarity of studies was assessed by evaluating the distribution of patient characteristics and study design across the direct comparisons in the network. If major imbalances in patient or study characteristics were detected that could influence the treatment effect, scenario analysis was used to explore the inhomogeneity. Meta-regression techniques could not be used to adjust for variations due to the limited number of studies available in the network.

\section{Data synthesis}

The identified trial evidence was used to perform an NMA within a Bayesian framework to simultaneously synthesize the results of the included studies and to obtain relative treatment effects. A linear model with normal likelihood distribution was used with flat (noninformative) prior distributions assumed for all outcomes. Prior distributions of the relative treatment effects were normal, with zero mean and a variance of 10,000. A uniform distribution ranging from zero to five was used as the prior of the interstudy SD.

For each outcome, fixed- and random-effects models were evaluated. The goodness of fit of each model to the data was assessed using the Deviance Information Criterion. The posterior densities for the outcomes of interest were estimated using the Markov Chain Monte Carlo simulations for each model. The results were based on 80,000 iterations on three chains, with a burn-in of 20,000 iterations. Convergence assessment was based on visual inspection of trace plots. Accuracy of the posterior estimates was assessed using the Monte Carlo error for each parameter (Monte Carlo error $<1 \%$ of the posterior SD). The models used in this study were based on those defined by Dias et $\mathrm{al}^{27}$ and were implemented using WinBUGS version 1.4.3 (MRC Biostatistics Unit, Cambridge, UK).

The posterior distributions were summarized with the corresponding median values to reflect the most likely value of the estimate, and the 2.5 and 97.5 percentile to capture the $95 \%$ credible interval $(95 \% \mathrm{CrI})$, which represents the range of true underlying effects with $95 \%$ probability. Pairwise comparisons for all treatments included in the network were calculated, including the relative effectiveness and the probability of each treatment being better than each of the rest. If studies reported mean values without any measure of uncertainty (SE, SD, 95\% CI), scenario analyses were performed excluding this study because of the lack of data; however, such studies were included with the reported mean value and an imputation for the SE.

The feasibility of an NMA to compare LABA/LAMA treatments with each other or with placebo was assessed. Considering the lack of placebo-controlled LABA/LAMA studies, TIO was included in the network to allow indirect comparisons with more treatments of interest. Extending the network by including TIO does have potential advantages such as strengthening inference and producing a more robust analysis. Two sets of analyses were performed, one including only LABA/LAMA treatments and placebo in the network (data not shown) and the other including LABA/LAMA treatments, TIO, and placebo in the network. The second analysis (including TIO) allowed for indirect comparisons with more relevant open and closed dual comparators because many studies lacked a placebo arm.

\section{Results}

\section{Search and selection results}

In total, 3,006 abstracts were identified, of which, 309 $(10.3 \%)$ abstracts were of interest based on predefined selection criteria, and full-text articles were obtained (Figure 1). Of the 4,720 identified registries, 159 were included. The registry screening results were merged with the abstracts and were screened against full-text selection criteria. The final NMA evidence base comprised 77 articles relating to 26 trials. These trials represented RCTs comparing LABA/LAMA combinations approved as of April 16, 2014 and TIO with each other or with placebo. The efficacy parameters shared between trials included lung function, defined as a difference in $\mathrm{CFB}$ in trough $\mathrm{FEV}_{1}$ and patient-reported outcomes, such as mean CFB in SGRQ total scores, difference in mean TDI focal scores, and change in rescue medication use estimated as mean number of puffs per day. Changes in efficacy parameters were compared at the 3-month (12-week) and 6-month time points (range, 24-26 weeks), to correspond to the duration of the UMEC/VI comparator trials (Table 1).

An overview of the study design, inclusion criteria, and background treatments of these trials is presented in Table 1. Study participants included individuals aged $\geq 40$ years with an established diagnosis of COPD and a smoking history of $\geq 10$ pack-years. Patients with moderate-to-very severe (GOLD stages II-IV) COPD, with an $\mathrm{FEV}_{1}$ of $\leq 70 \%$ of predicted normal value, and no inclusion criterion related to the number of exacerbations in the previous year were considered $^{21}$; potential exceptions were the SPARK study, 
A

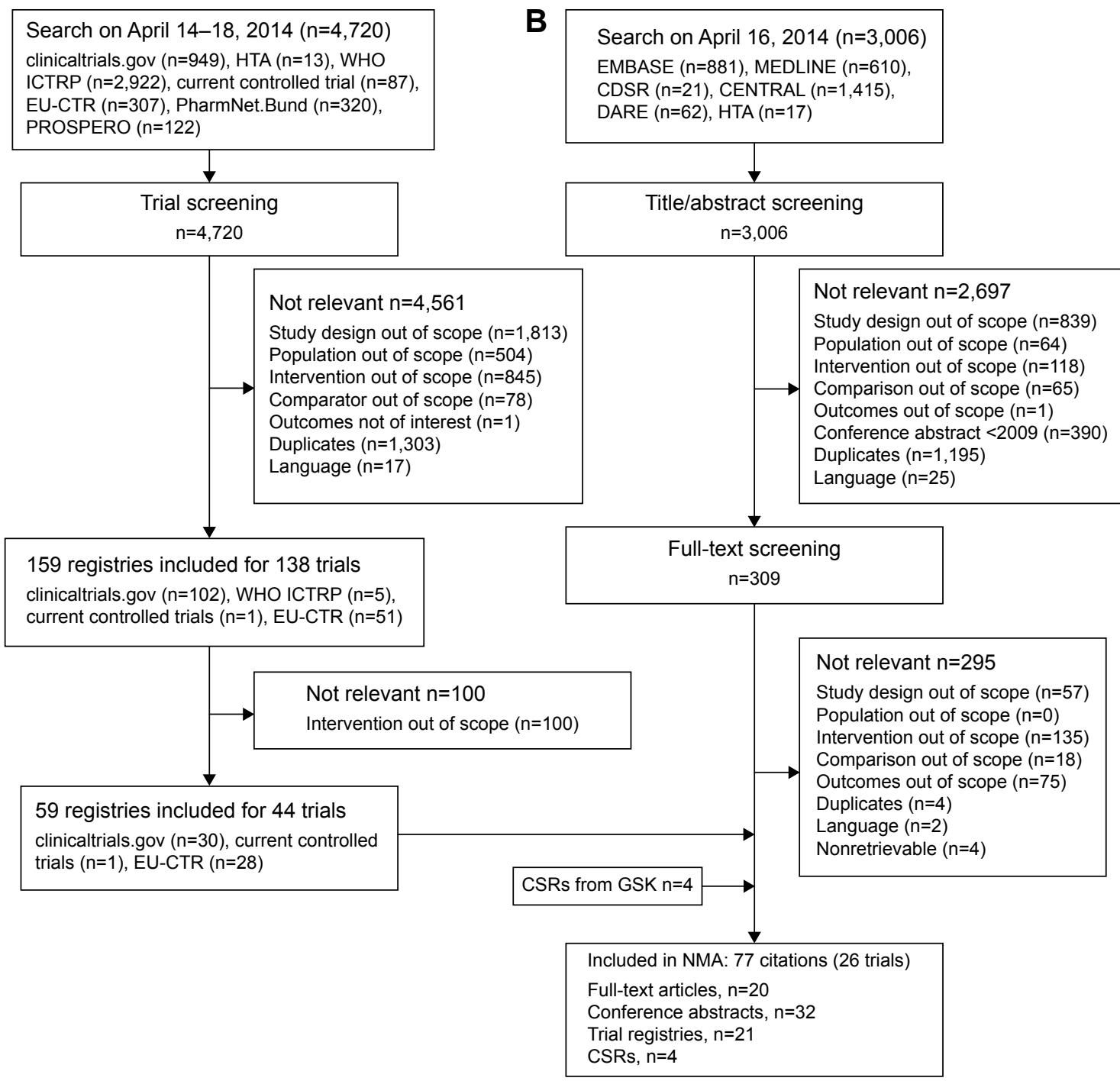

Figure I Summary of study-flow (A) registries (B) study selection.

Abbreviations: CDSR, Cochrane Database of Systematic Review; CSR, clinical study report; DARE, Database of Abstracts of Reviews of Effects; EMBASE, Excerpta Medica dataBASE; EU-CTR, European Union Clinical Trials Register; HTA, Health Technology Assessment Database; GSK, GlaxoSmithKline; MEDLINE, Medical Literature Analysis and Retrieval System Online; NMA, network meta-analysis; PROSPERO, international prospective register of systematic review; WHO ICTRP, World Health Organization International Clinical Trials Registry Platform.

which included no patients with moderate COPD, but only patients with a history of $>1$ moderate or severe exacerbation during the past year, ${ }^{16}$ and the UMEC/VI studies, all of which included patients who had breathlessness (modified Medical Research Council scale $\geq 2)$. ${ }^{6,928}$ Regarding the background treatments, most of the studies allowed the use of inhaled corticosteroids (ICSs), while the use of LAMAs, LABAs, or LABA/ICS was not allowed.

Table 2 presents an overview of the primary patient characteristics (and potential treatment effect modifiers in COPD), including age, sex, smoking status, ICS use, COPD duration, number of pack-years, predicted $\mathrm{FEV}_{1}$, and proportion of patients with severe or very severe disease. The patients were primarily male (49\%-99\%), with a mean age above 60 years (60-68 years) and heavy smokers (36-69.2 pack-years). Some variation in ICS use was detected (25\%-76\%), with Aaron et $\mathrm{al}^{20}$ and Tashkin et al ${ }^{18}$ reporting that $<30 \%$ of patients used ICS at baseline in at least one of the treatment arms.

Overall, patient characteristics were comparable between UMEC/VI and other dual-bronchodilator trials. No major imbalances in the study and patient characteristics were observed between direct comparisons in the network that could act as effect modifiers of the relative treatment effects; therefore, an NMA was deemed to be feasible. ${ }^{26}$ The results of the risk of bias assessment at study level for all studies included in the NMA are summarized in Table S3. 


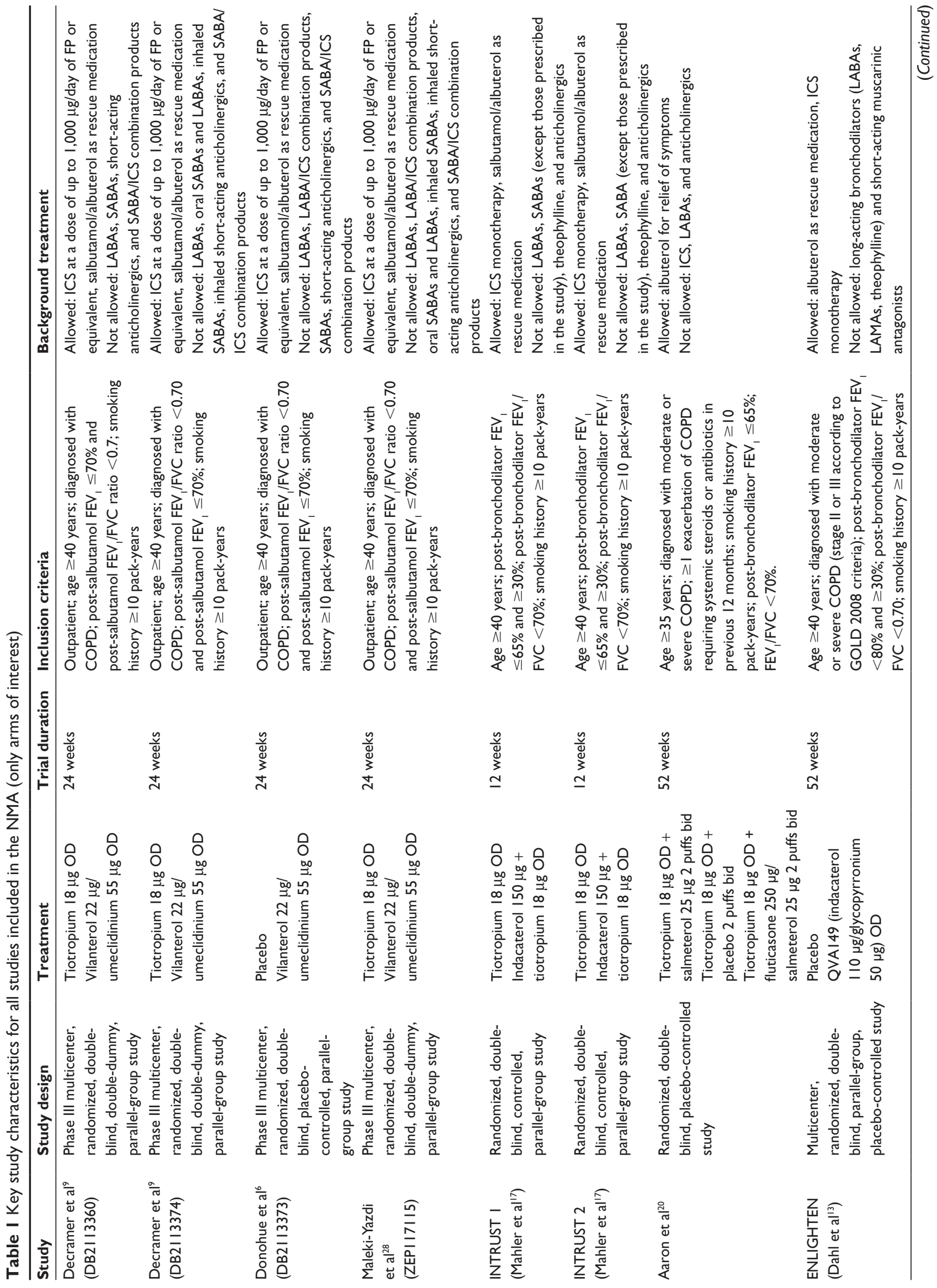




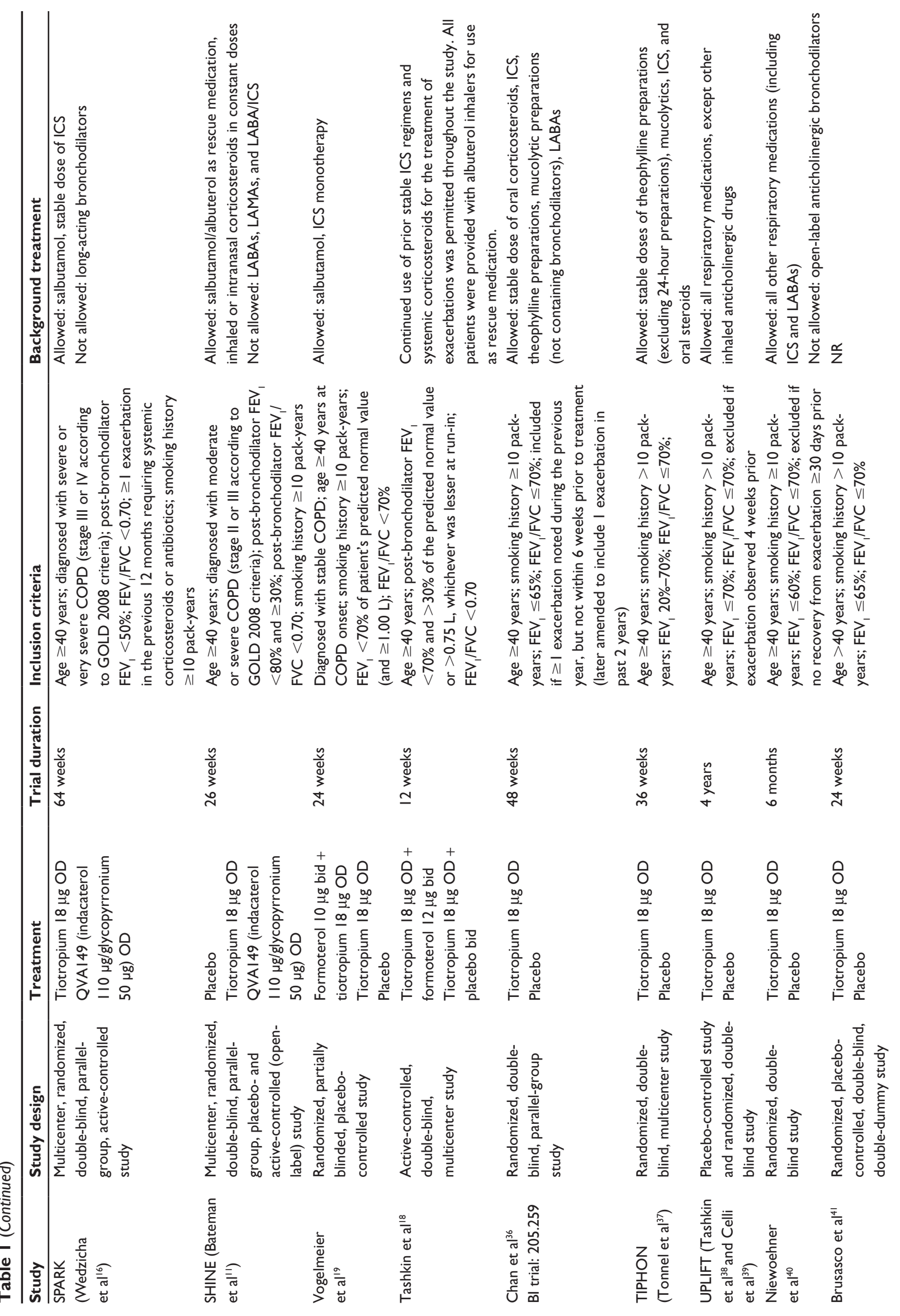



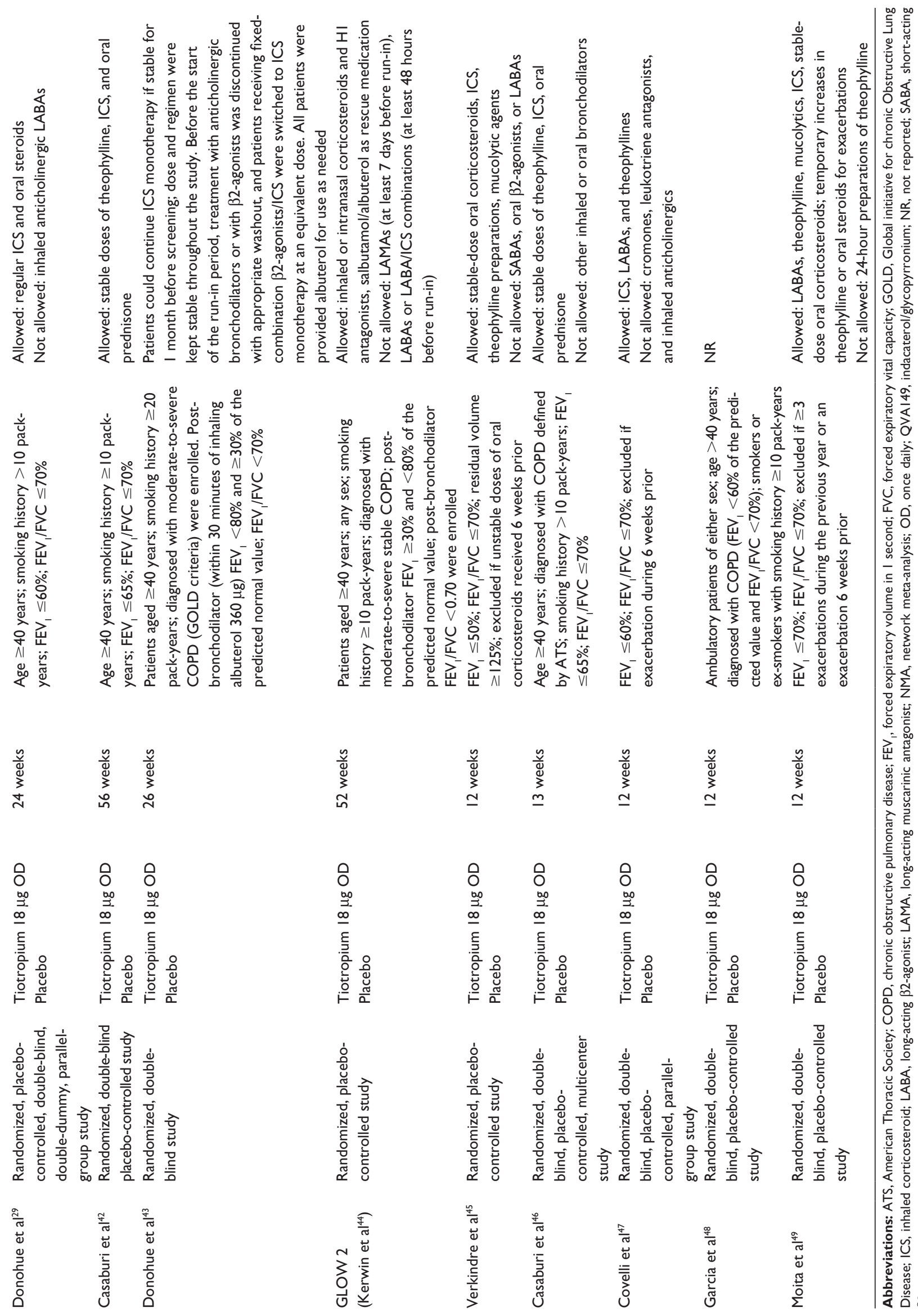


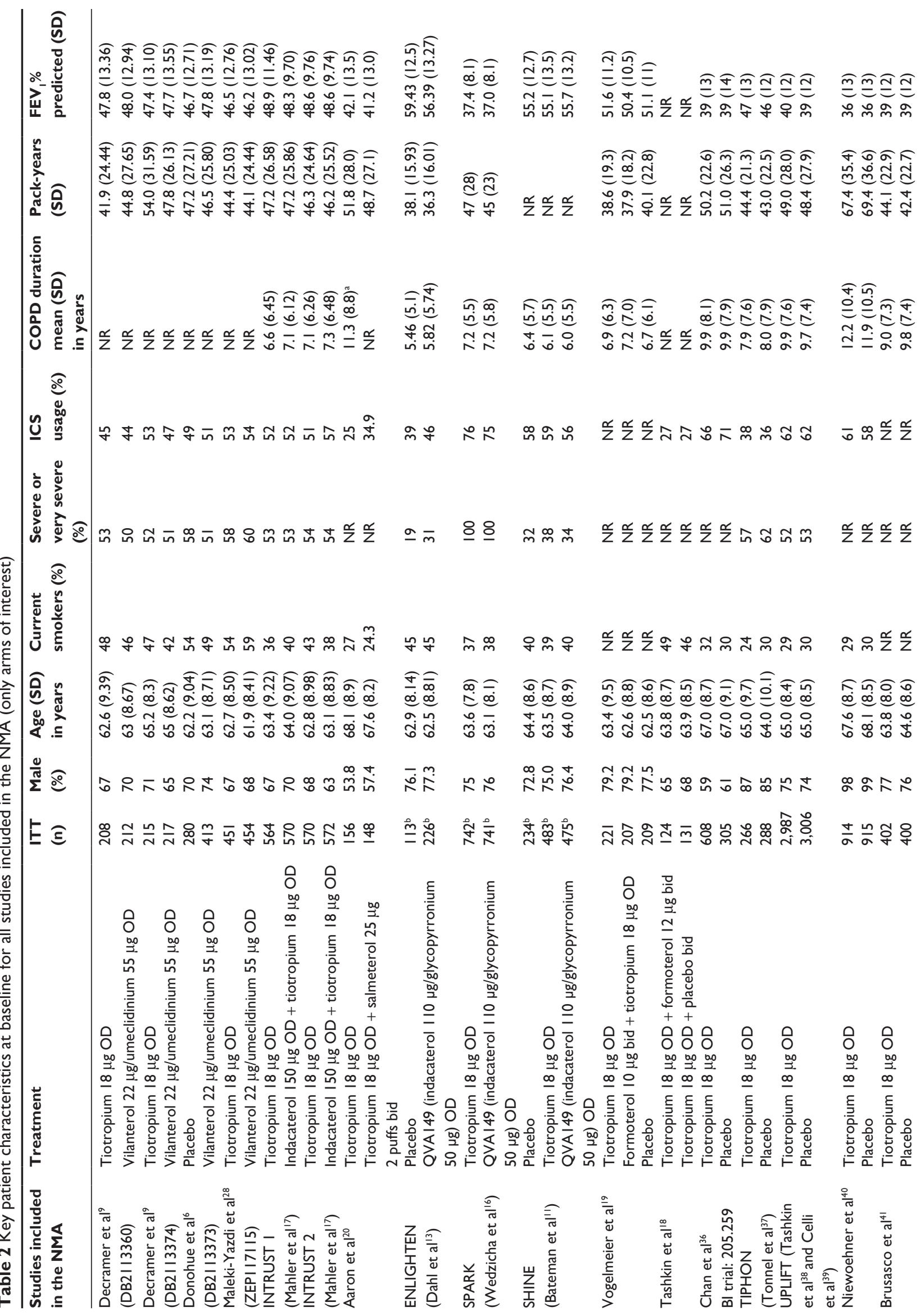




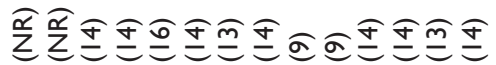

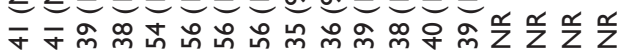

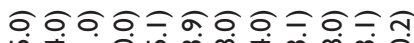

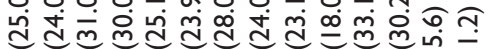

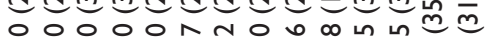

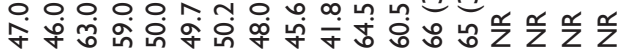

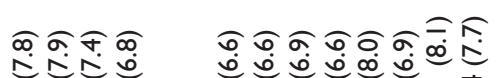
승

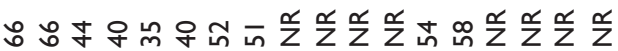

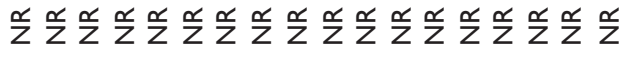

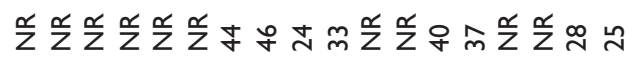

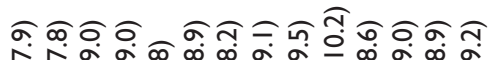

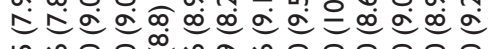

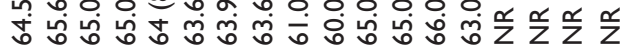

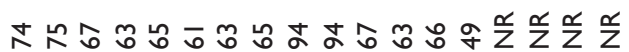

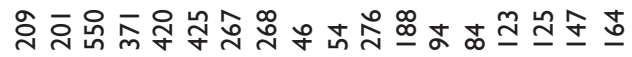

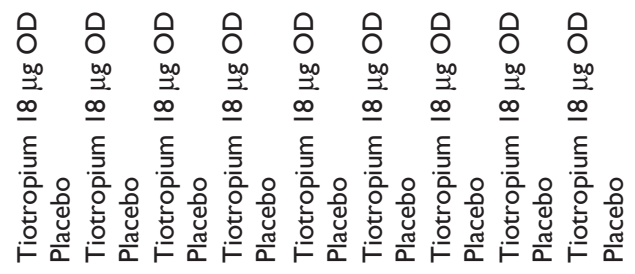

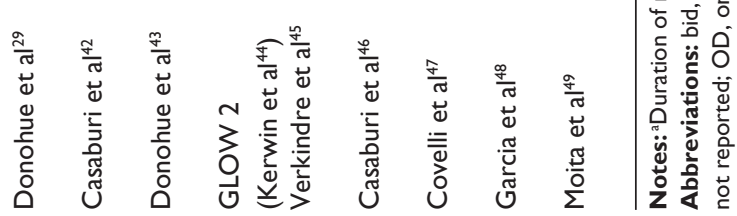

\section{Bayesian NMA}

Figure 2 presents the overall network of studies in the analysis. These studies were identified in the SLR comparing QVA149, FOR + TIO, SAL + TIO, IND + TIO, or UMEC/VI with TIO OD or placebo as common comparators. The common endpoints in the identified studies were trough $\mathrm{FEV}_{1}$, SGRQ total scores, TDI focal scores, and rescue medication use at 24 weeks and within the time margins around these time points.

\section{Trough FEV,}

In total, 14 studies were included for the $\mathrm{FEV}_{1}$ endpoint (Figure 2 and Table 3). Combination therapies of UMEC/ VI, QVA149, and TIO + SAL were more efficacious than placebo, and UMEC/VI and QVA149 were more efficacious than TIO monotherapy as indicated by CFB in mean trough $\mathrm{FEV}_{1}$ at 24 weeks. The difference in CFB in mean trough $\mathrm{FEV}_{1}$ numerically favored UMEC/VI in comparison to both QVA149 (estimated difference [ED], $14.14 \mathrm{~mL}$; 95\% CrI: $-14.18,42.25)$ and TIO + SAL (ED, $67.40 \mathrm{~mL} ; 95 \%$ CrI: $-25.25,159.40)$, although no statistically or clinically significant differences were observed between the LABA/ LAMA combinations (Figure 3A and Table 4).

\section{SGRQ total scores}

Fourteen studies were included in the analysis of SGRQ total scores (Figure 2 and Table 3 ). All the combination therapies, including UMEC/VI, QVA149, TIO + SAL, and TIO + FOR, demonstrated significantly higher efficacy in CFB in SGRQ total scores compared with placebo and TIO at 24 weeks. UMEC/VI was not significantly different from QVA149 (ED, 0.18; 95\% CrI: -1.28, 1.63), TIO + SAL (ED, -0.11 ; 95\% CrI: $-1.84,1.61$ ), and TIO + FOR (ED, $-0.68 ; 95 \%$ CrI: $-1.77,0.40$ ) (Figure 3B and Table 4). As a scenario analysis, SE was imputed for the study by Donohue et al (TIO vs placebo), ${ }^{29}$ and this study was included in the network, having marginal impact on the results.

\section{TDI focal scores}

In total, ten studies were included in the TDI analysis (Figure 2 and Table 3). Combination therapies of UMEC/VI and QVA149 were more efficacious than placebo, and QVA149 was more efficacious than TIO monotherapy in TDI focal score at 24 weeks. UMEC/VI was not significantly different from QVA149 (ED, $-0.30 ; 95 \%$ CrI: $-0.73,0.13$ ) and $\mathrm{TIO}+\mathrm{SAL}$ (ED, $0.58 ; 95 \%$ CrI: $-0.33,1.50$ ) (Figure $3 \mathrm{C}$ and Table 4). The addition of imputed evidence from the Donohue et al study ${ }^{29}$ had marginal impact on the results. 
A

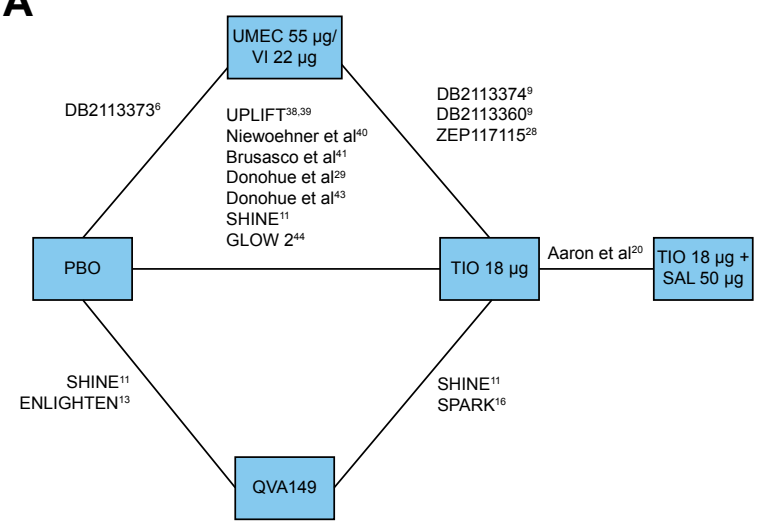

C

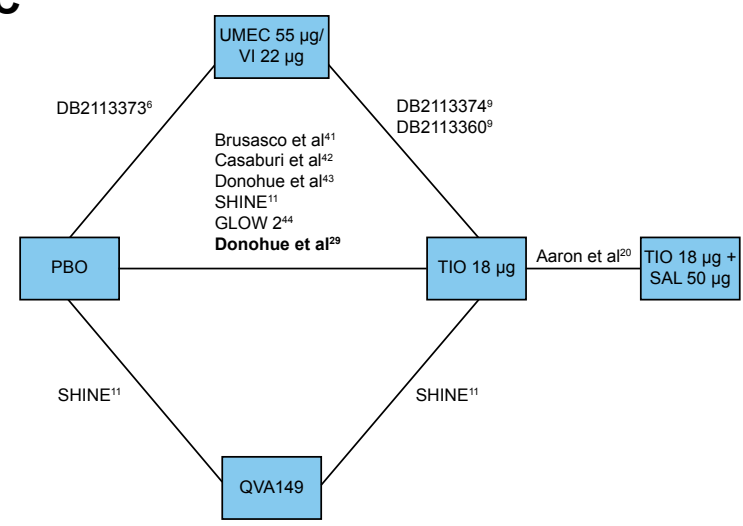

B

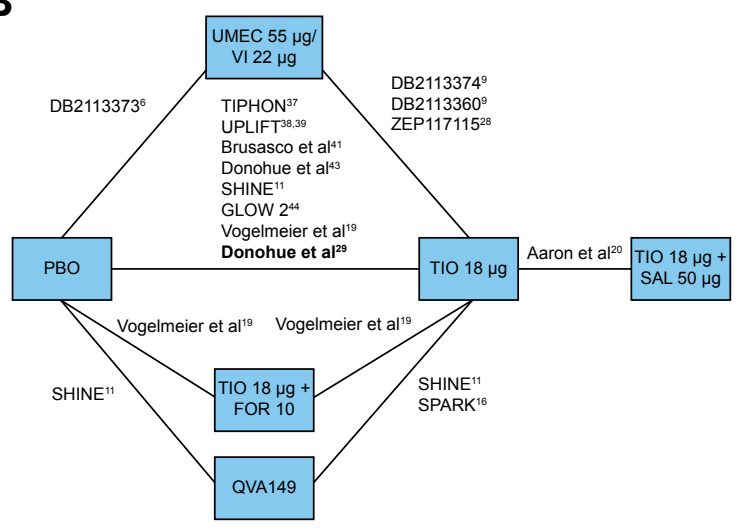

D

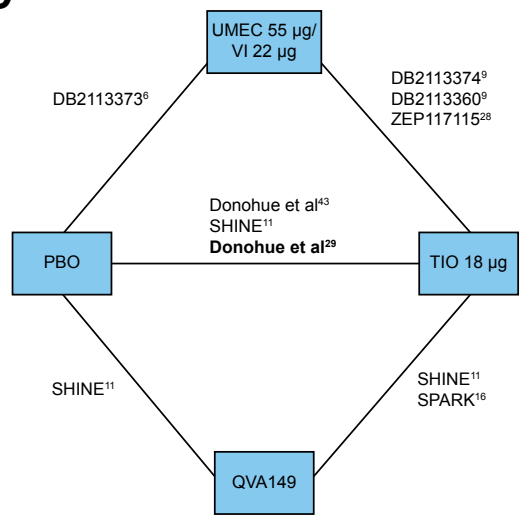

Figure 2 Overall network of studies in the NMA analysis of UMEC/VI versus LABA/LAMA combination therapies evaluated at 24 weeks for (A) trough FEV , (B) SGRQ total score, (C) TDI focal score, and (D) rescue medication use.

Notes: Studies in bold represent those that report only mean values without reporting SE, SD, and 95\% Cl. Studies DB2। I 3360 and DB2 I I 3374 from Decramer et al. ${ }^{9}$ Study DB2 II 3373 from Donohue et al. ${ }^{6}$ Study ZEPII7III from Maleki-Yazdi et al. ${ }^{28}$

Abbreviations: $\mathrm{Cl}$, confidence interval; $\mathrm{FEV}$, forced expiratory volume in I second; FOR, formoterol; LABA, long-acting $\beta 2$-agonist; LAMA, long-acting muscarinic antagonist; NMA, network meta-analysis; PBO, placebo; QVAI49, indacaterol/glycopyrronium; SAL, salmeterol; SD, standard deviation; SE, standard error; SGRQ, St George's Respiratory Questionnaire; TDI, transitional dyspnoea index; TIO, tiotropium; UMEC, umeclidinium; VI, vilanterol.

\section{Rescue medication use}

In total, seven studies were included in the rescue medication use network (Figure 2 and Table 3). For rescue medication use at 24 weeks, the combination therapies of UMEC/VI and QVA149 were more efficacious than placebo and TIO. No significant difference was observed between UMEC/VI and QVA149 (ED, 0.02; 95\% CrI: -0.27, 0.32) (Figure 3D and Table 4) with imputed evidence from the Donohue et $\mathrm{al}^{29}$ study having marginal impact.

\section{Discussion}

This study evaluated the comparative efficacy of UMEC/VI $55 / 22 \mu \mathrm{g}$ with all the available open and closed dual-combination bronchodilators in patients with moderate-to-very severe COPD who were eligible to receive maintenance bronchodilator therapy. Four endpoints, including mean CFB in trough $\mathrm{FEV}_{1}$, CFB in SGRQ total scores, TDI focal scores, and CFB in rescue medication use, were selected and analyzed because they were consistently reported across all the studies and deemed as important endpoints in clinical practice. The Bayesian NMA showed that for each endpoint, UMEC/VI was similar to all the other dual fixed or open LABA/LAMA combination bronchodilators (IND + TIO, TIO + SAL, TIO + FOR, and QVA149) available at the time of this analysis. Indirect treatment comparison within a frequentist framework by using Bucher's method also showed consistent results for all the aforementioned efficacy parameters (data not shown). ${ }^{30}$ This suggests that combination therapies of LABA/LAMA are broadly comparable across the most common endpoints evaluated in RCT settings. These aforementioned observations are consistent with two other recent NMAs, which suggested that bronchodilator monotherapies are broadly similar across a range of clinical endpoints. ${ }^{31}$ One NMA, however, showed that newer OD LABAs were likely to be more effective compared with bid LABAs at improving $\mathrm{FEV}_{1}$ and SGRQ scores. ${ }^{32}$ The NMA focused on four most commonly 


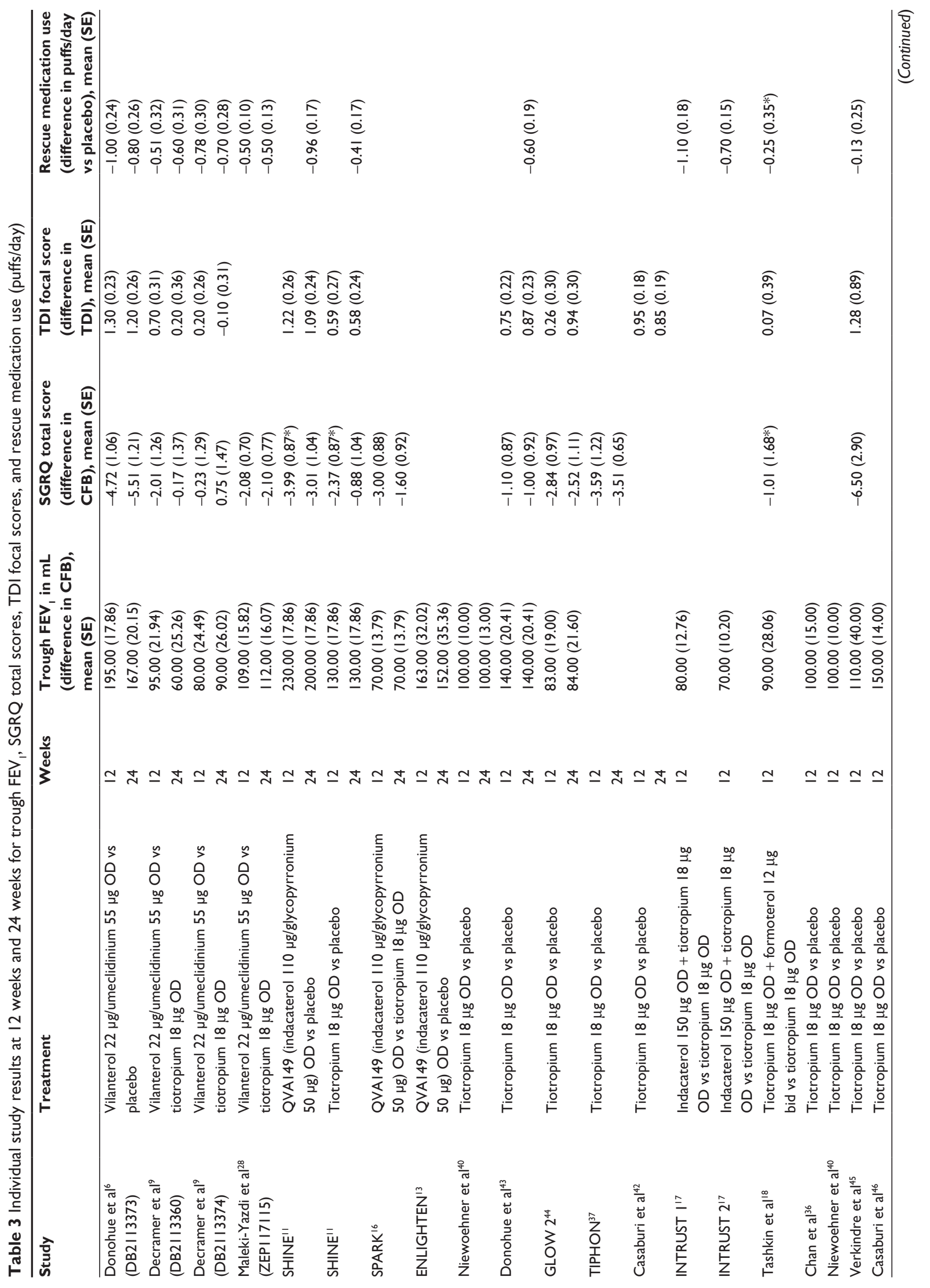




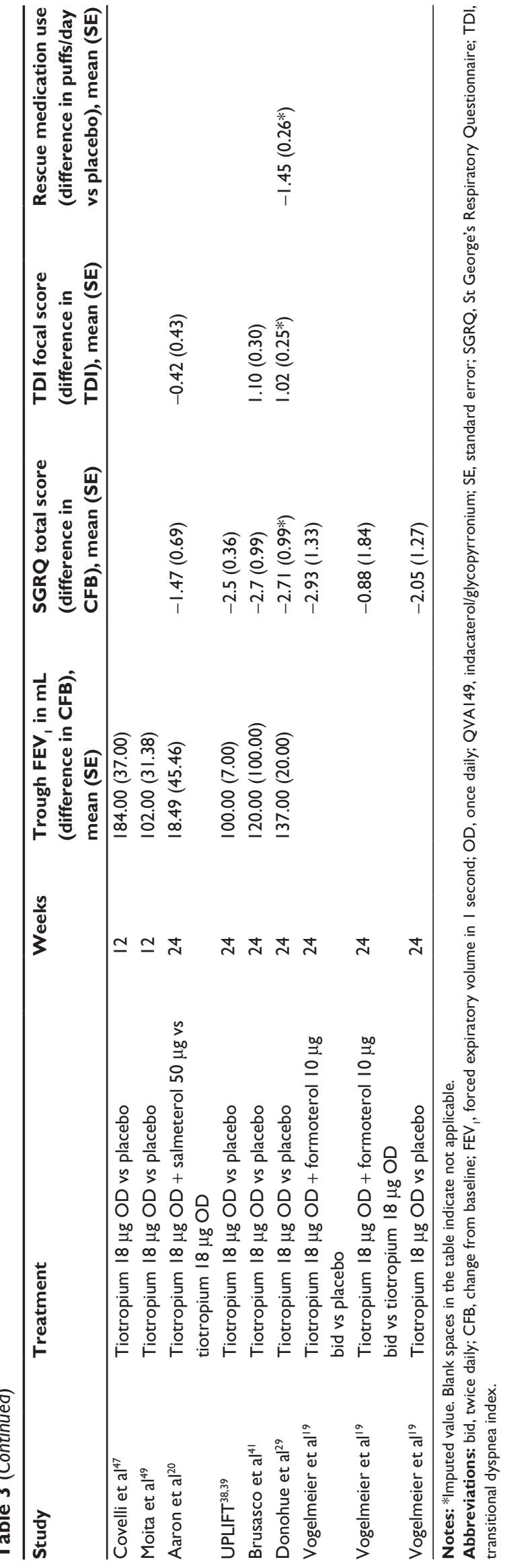

reported endpoints in RCTs of bronchodilators. Endpoints such as adverse events, exercise tolerance, and exacerbations were excluded. Our feasibility assessment suggested that the definitions of adverse events, exacerbations, and exercise tolerance tests used in manufacturer-conducted trials differed significantly across various LABA and/or LAMA treatments, preventing robust comparison. The patients assessed in most trials reported a limited history of exacerbations and in those trials enriched for patients with exacerbations; no placebo comparisons were included. Moreover, exacerbation was not a key endpoint in most selected studies, including the UMEC/ VI studies. Patients with exacerbations were withdrawn from UMEC/VI studies at the first event, ${ }^{6,9,28}$ thereby limiting the available evidence to the risk of a first event but providing no data on exacerbation rates. Other trials designed to examine exacerbations included the SPARK study ${ }^{16}$ in which the LABA/LAMA combination (QVA149) was compared with two LAMAs and was reported to provide superior reductions in the rate of moderate or severe exacerbations versus GLY but not versus TIO. This benefit of QVA149 was also entirely confined to patients using concurrent corticosteroids. ${ }^{16}$ Similarly, Aaron et $\mathrm{al}^{20}$ reported no exacerbation benefit with $\mathrm{TIO}+\mathrm{SAL}$ versus TIO in patients not using corticosteroids. In the UMEC/VI studies, approximately $50 \%$ of patients used corticosteroids and a superior exacerbation benefit was observed on the time to the first exacerbation with UMEC/VI versus placebo ${ }^{6}$ and versus TIO but only in the largest of three similar 6-month trials. ${ }^{28}$ Consequently, uncertainty still exists on this endpoint, which is out of scope for this NMA.

These meta-analyses also demonstrated that monobronchodilators when compared with placebo generally failed to improve total SGRQ scores by $\geq 4$ units and TDI focal scores by $\geq 1$ unit at 6 months, which are the minimal clinically important differences for each of these commonly used patientreported outcomes, even when the trough $\mathrm{FEV}_{1}$ improved by at least $100 \mathrm{~mL}$ compared with placebo..$^{32}$ In the current analysis, we observed that UMEC/VI consistently demonstrated clinically important benefits versus placebo and statistically significant benefits versus TIO at 6 months, which were broadly comparable to any alternative dual-bronchodilator combinations. These findings highlight that LAMA or LABA monotherapy alone may not always provide all patients with sustained benefits enabling freedom from recurrence of COPD symptoms.${ }^{33}$ Dual bronchodilators, which are sparingly used in current clinical practice, may provide optimal symptom control in addition to maximum bronchodilation to appropriate COPD patients. ${ }^{34}$ Overall, both QVA149 and UMEC/VI demonstrated beneficial effects compared with monotherapy at 24 weeks, 
A Mean trough FEV 1 at 24 weeks $(\mathrm{mL})-$ UMEC $55 \mu \mathrm{g} / \mathrm{VI} 22 \mu \mathrm{g}$ vs comparators

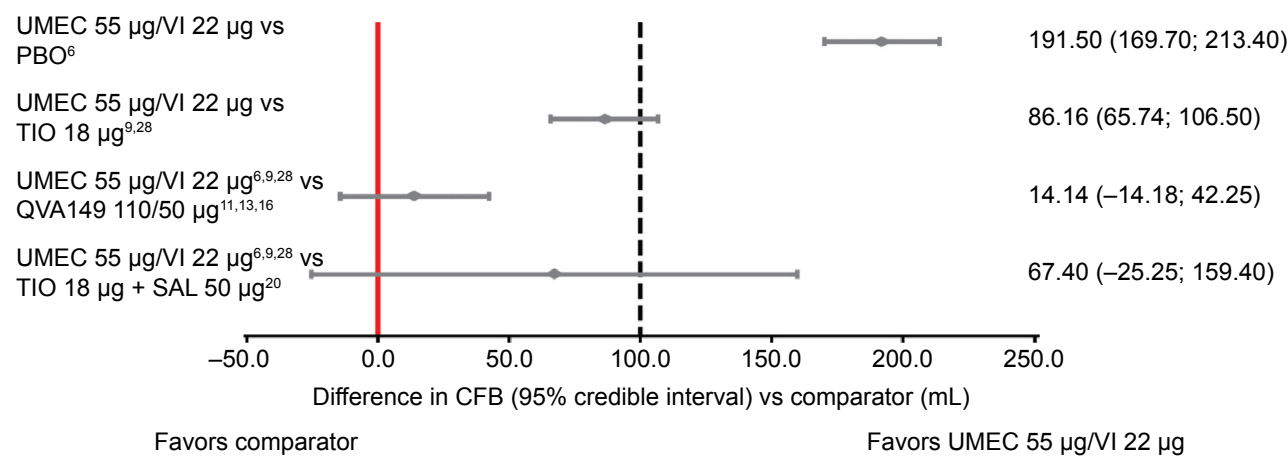

B Mean SGRQ total score at 24 weeks - UMEC $55 \mu \mathrm{g} / \mathrm{VI} 22 \mu \mathrm{g}$ vs comparators

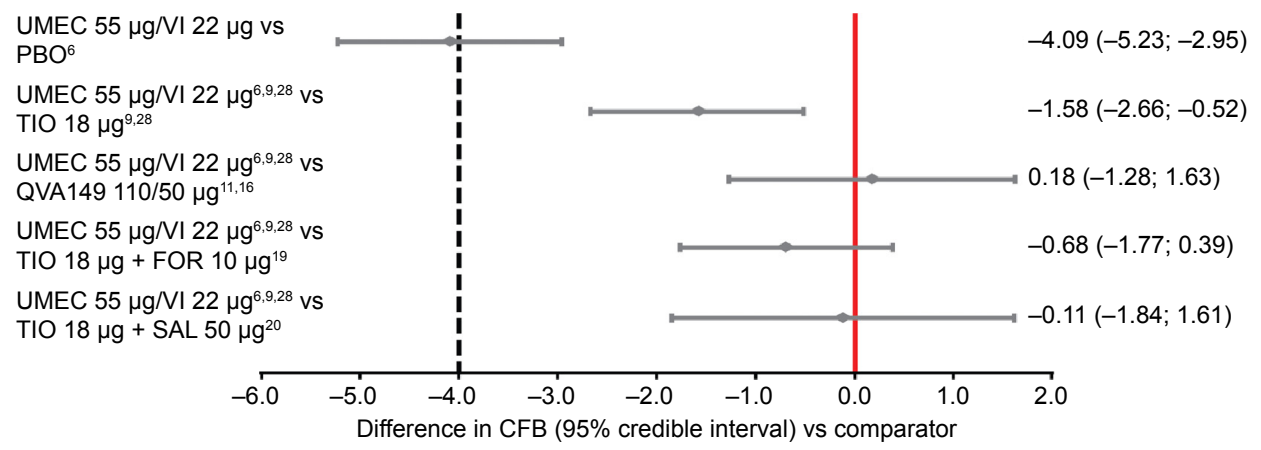

Favors UMEC $55 \mu \mathrm{g} / \mathrm{VI} 22 \mu \mathrm{g} \quad$ Favors comparator

C Mean TDI focal score at 24 weeks - UMEC $55 \mu \mathrm{g} / \mathrm{VI} 22 \mu \mathrm{g}$ vs comparators

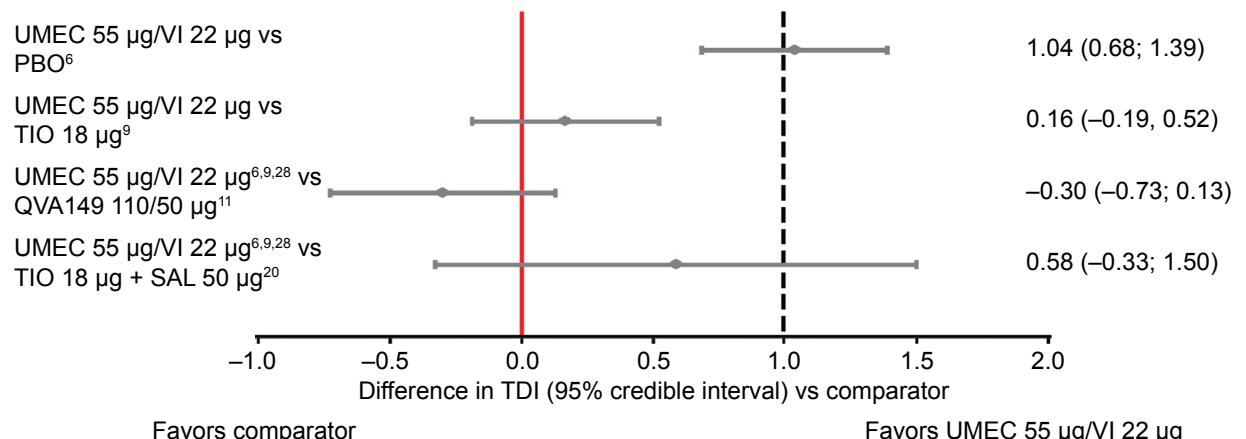

D Rescue medication use (puffs/day) at 24 weeks - UMEC/N1 55/22 $\mu \mathrm{g}$ vs comparators

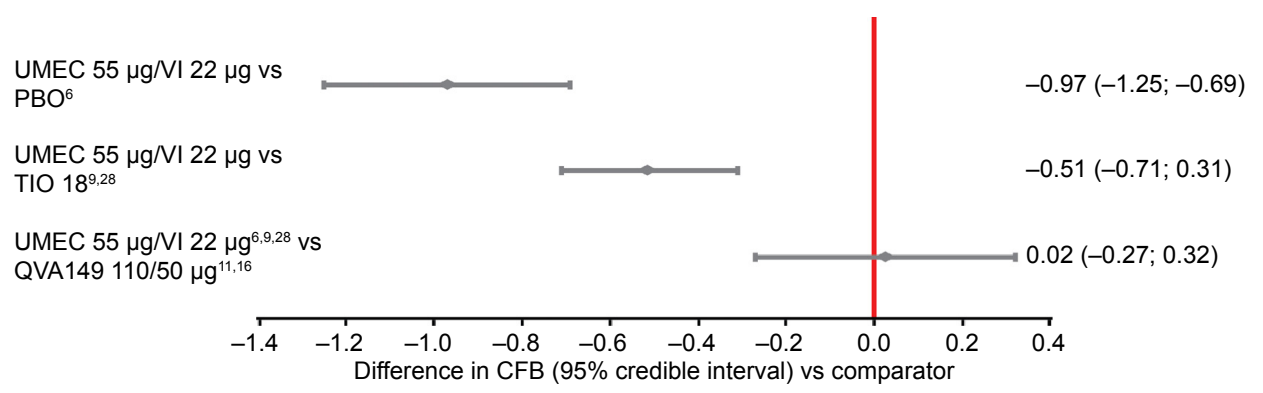

Favors UMEC $55 \mu \mathrm{g} / \mathrm{VI} 22 \mu \mathrm{g}$

Favors comparator

Figure 3 Forest plot for (A) mean trough $\mathrm{FEV}_{1}$, (B) mean SGRQ total scores, (C) mean TDI focal scores, and (D) mean rescue medication use of UMEC $55 \mu \mathrm{g} / \mathrm{VI} 22 \mu \mathrm{g}$ versus comparators at 24 weeks.

Notes: Dotted lines included in panels $(\mathbf{A}-\mathbf{C})$ indicate the MCIDs versus placebo if these have been defined: these have been included in the graph for reference purpose only. The values shown on the right of each figure represent mean $(95 \% \mathrm{Cl})$.

Abbreviations: CFB, change from baseline; FEV , forced expiratory volume in I second; FOR, formoterol; MCID, minimal clinically important difference; PBO, placebo; QVAI49, indacaterol/glycopyrronium; SAL, salmeterol; SGRQ, St George's Respiratory Questionnaire; TDI, transitional dyspnea index; TIO, tiotropium; UMEC, umeclidinium; VI, vilanterol. 


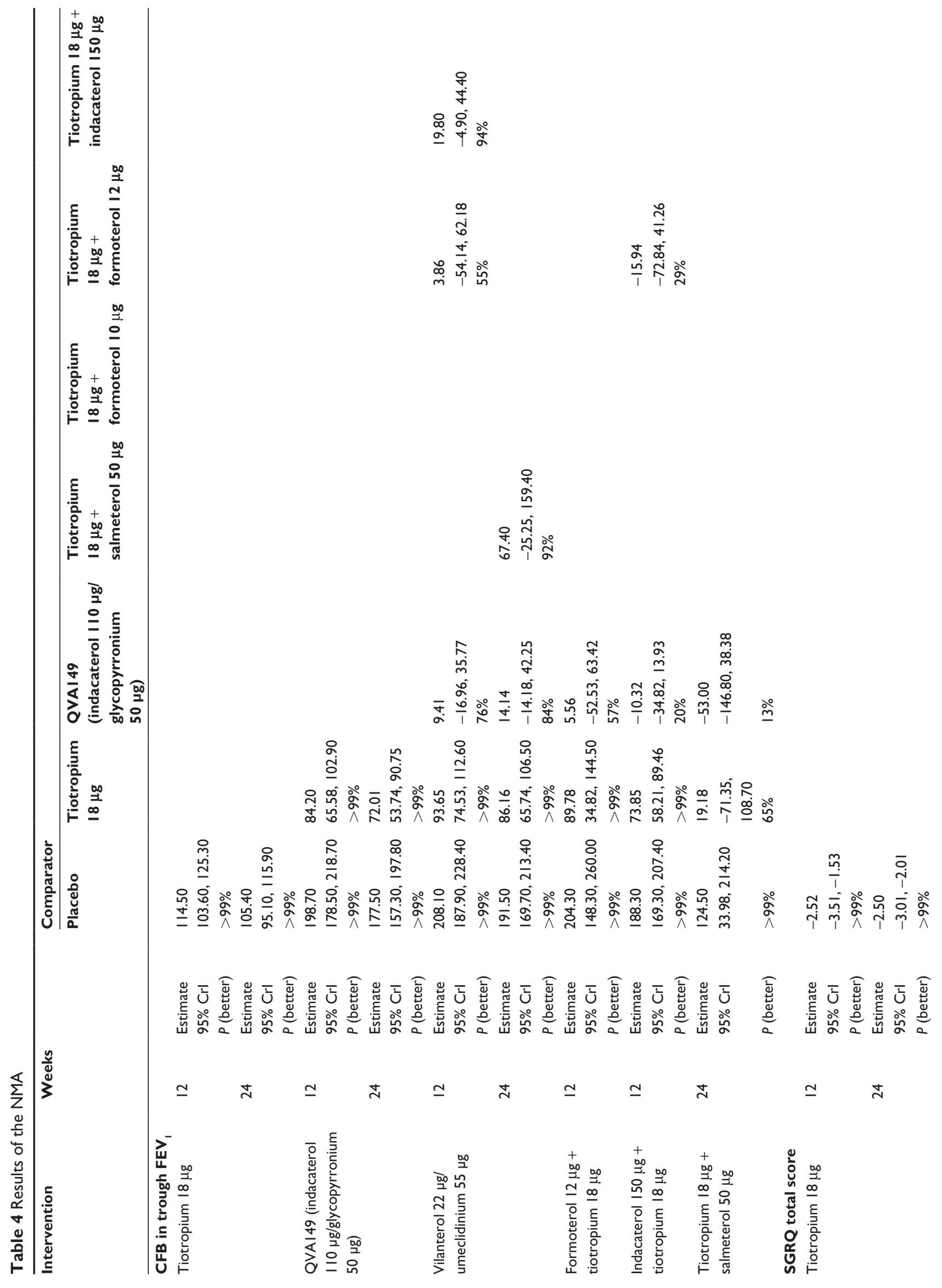




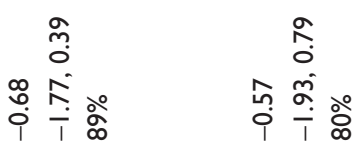

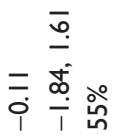
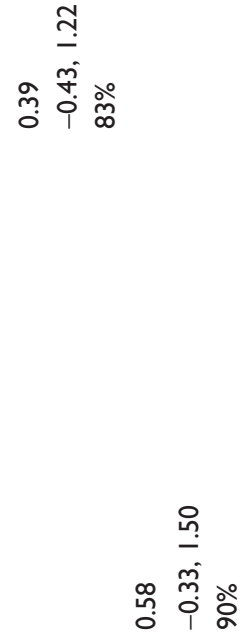

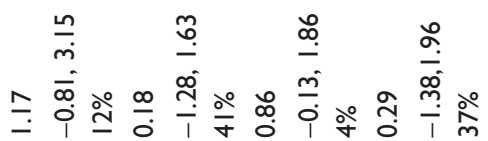

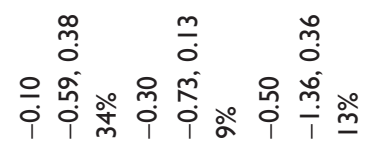

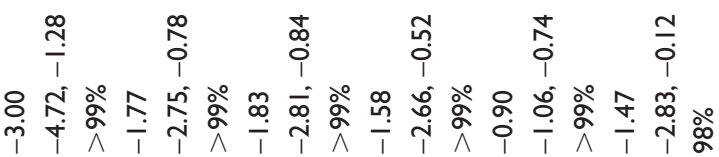

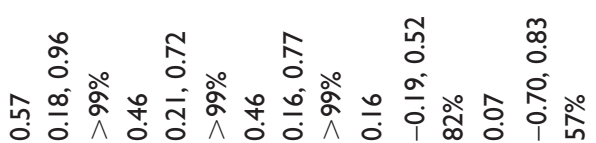

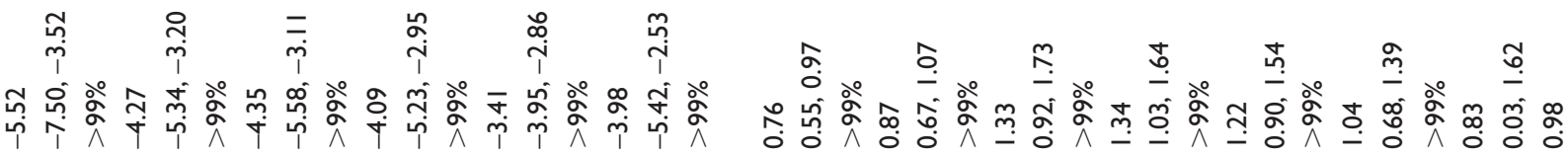

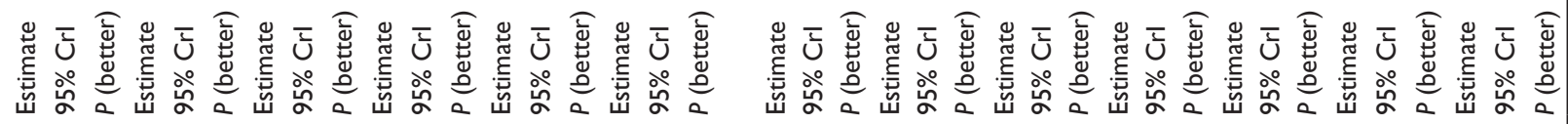

\begin{tabular}{|c|c|c|c|c|c|c|c|}
\hline 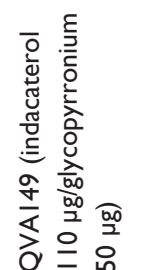 & 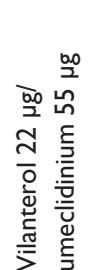 & 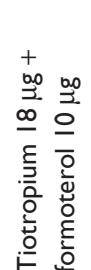 & 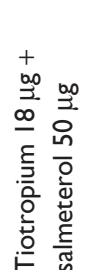 & 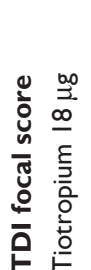 & 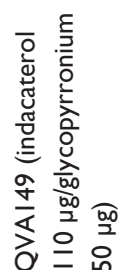 & 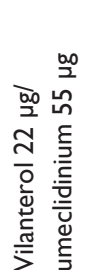 & 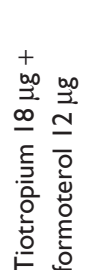 \\
\hline
\end{tabular}

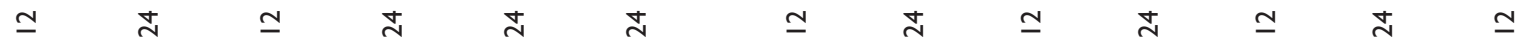




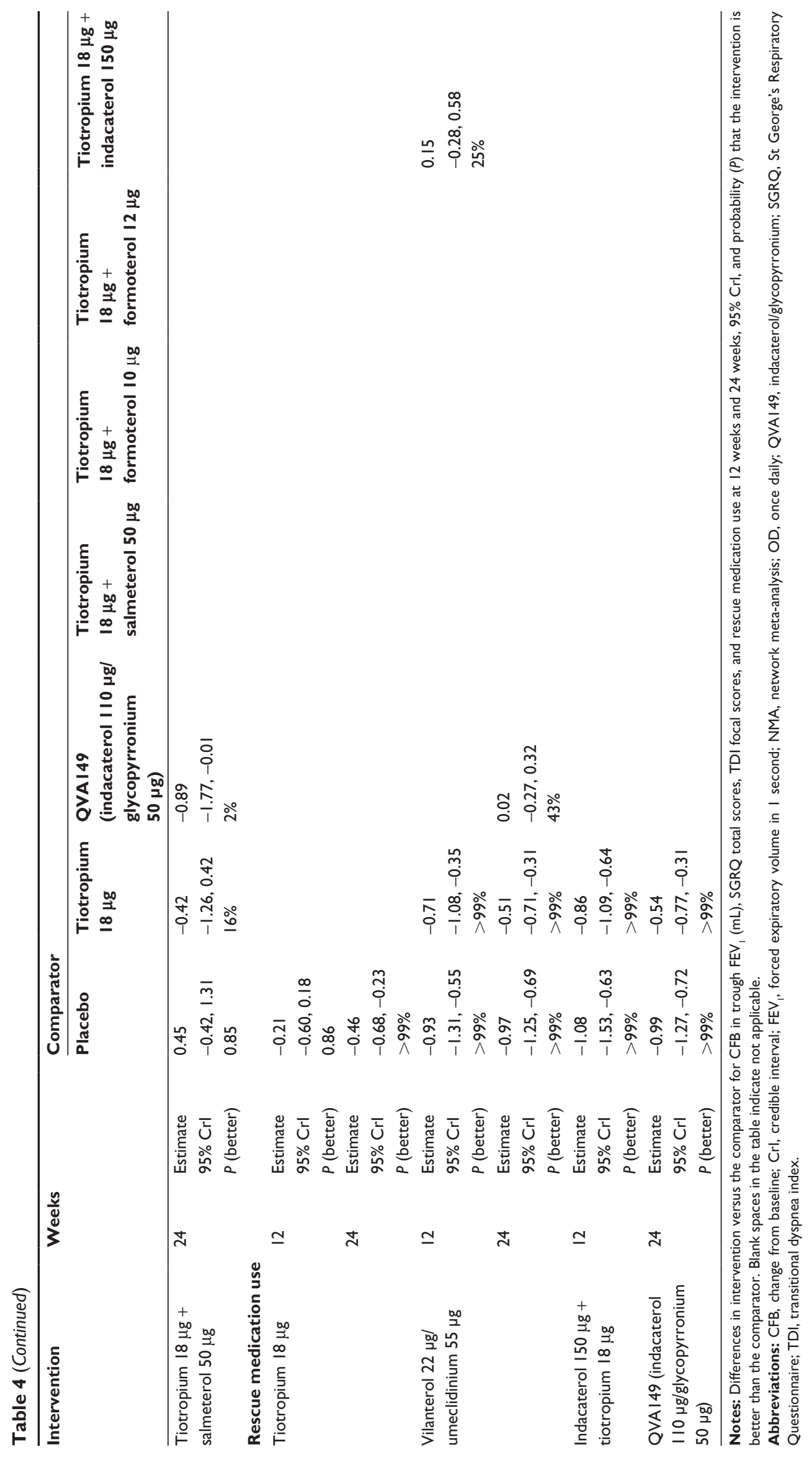


and these findings were further corroborated by the supplementary analysis performed at 12 weeks. This NMA also revealed comparable efficacy of UMEC/VI to open dual-combination bronchodilators. However, caution is needed in this regard, as the advantage of combining two long-acting bronchodilators in a single inhaler in terms of improved medication adherence leading to potentially better outcomes may become evident only in studies of a less controlled nature.

\section{Limitations}

A potential limitation of this analysis is the low number of studies for some of the treatments (eg, TIO18 + SAL50) and the absence of direct evidence with other active treatments of interest. The fact that for these treatments only indirect comparison (via TIO or placebo) was available is reflected in the uncertainty of the relative efficacy results (ie, wide CIs).

An additional limitation is that studies reporting data for aclidinium/FOR were not identified.

A further limitation of the analysis, as with all metaanalyses, is the potential influence of confounders. A metaregression to adjust for possible confounders was not feasible because of the limited number of studies included in each analysis. Although two studies ${ }^{18,20}$ reported lower ICS use at baseline, it was not possible to design scenario analyses excluding these studies. In both cases, it would result in the loss of a comparator in the network and would not affect the other relative efficacy estimates due to the shape of the network. Because recent NMAs ${ }^{31,32,35}$ evaluating longacting bronchodilators in COPD did not suggest the relative efficacy estimates to be greatly affected by this and other potential effect modifiers, the impact of this imbalance was not believed to be a likely source of bias. Although the studies were similar enough to be included in an NMA, residual confounding may exist in these aggregated data.

\section{Conclusion}

Based on the results of this 6-month NMA of the available RCTs reporting on efficacy outcomes in terms of trough $\mathrm{FEV}_{1}$, SGRQ total scores, TDI focal scores, and rescue medication use, UMEC/VI is comparable to QVA149 and is expected to be at least comparable to the remaining dualbronchodilator combinations.

\section{Statement of originality/clinical relevance}

With the recent introduction of a new class of fixed-dose combination bronchodilators (UMEC/VI and QVA149) and several others under development, assessing their efficacy relative to each other and with open dual combinations is desirable. Therefore, this study aimed to perform an SLR and to synthesize, by means of a Bayesian NMA, the published evidence on the efficacy of the fixed combination of UMEC/VI (55/22 $\mu \mathrm{g}$ OD) with that of all available dual-bronchodilator combinations in single or separate inhalers. The analysis was conducted with TIO and placebo as common comparators. The relative efficacy of the treatments was assessed at 12 weeks and 24 weeks in terms of lung function (trough $\mathrm{FEV}_{1}$ ), health status (SGRQ total scores), TDI focal scores, and rescue medication use. To our knowledge, this is the first study to compare fixed-dose combination bronchodilators with other such fixed-dose and open combinations and to provide valuable evidence for clinicians and payers to choose the most optimal medication for their patients.

\section{Acknowledgments}

This study was funded by GlaxoSmithKline. Medical writing services were provided by Dr Annirudha Chillar of Cactus Communications and funded by GlaxoSmithKline.

\section{Author contributions}

All authors contributed to the conception and design of the study. AK and ELH contributed to data acquisition, and all five authors contributed to data analysis and interpretation, drafting and critically revising the paper, and agree to be accountable for all aspects of the work.

\section{Disclosure}

SMC, ASI, and YSP are employees of GlaxoSmithKline and hold stocks at GlaxoSmithKline. AK and ELH are employees of Mapi Group and were consultants to GlaxoSmithKline on this study. The authors report no conflicts of interest in this work.

\section{References}

1. WHO methods and data sources for global causes of death 2000-2011. Global Health Estimates Technical Paper WHO/HIS/HSI/GHE/2013.3. Available from: http://www.who.int/healthinfo/statistics/GlobalCOD_ method.pdf. Accessed April 16, 2014.

2. Cazzola M, Noschese P, Salzillo A, De Giglio C, D’Amato G, Matera MG. Bronchodilator response to formoterol after regular tiotropium or to tiotropium after regular formoterol in COPD patients. Respir Med. 2005;99:524-528.

3. van Noord JA, Aumann JL, Janssens E, et al. Comparison of tiotropium once daily, formoterol twice daily and both combined once daily in patients with COPD. Eur Respir J. 2005;26:214-222.

4. van Noord JA, Aumann JL, Janssens E, et al. Effects of tiotropium with and without formoterol on airflow obstruction and resting hyperinflation in patients with COPD. Chest. 2006;129:509-517.

5. Celli B, Crater G, Kilbride S, et al. Once-daily umeclidinium/vilanterol 125/25 mcg in COPD: a randomized, controlled study. Chest. Epub 2014 Jan 1. 
6. Donohue JF, Maleki-Yazdi MR, Kilbride S, Mehta R, Kalberg C, Church A. Efficacy and safety of once-daily umeclidinium/vilanterol 62.5/25 mcg in COPD. Respir Med. 2013;107:1538-1546.

7. Feldman G, Walker RR, Brooks J, Mehta R, Crater G. 28-day safety and tolerability of umeclidinium in combination with vilanterol in COPD: a randomized placebo-controlled trial. Pulm Pharmacol Ther. 2012;25:465-471.

8. Kelleher DL, Mehta RS, Jean-Francois BM, et al. Safety, tolerability, pharmacodynamics and pharmacokinetics of umeclidinium and vilanterol alone and in combination: a randomized crossover trial. PLoS One. 2012; 7:e50716.

9. Decramer M, Anzueto A, Kerwin E, et al. Efficacy and safety of umeclidinium plus vilanterol versus tiotropium, vilanterol, or umeclidinium monotherapies over 24 weeks in patients with chronic obstructive pulmonary disease: results from two multicentre, blinded, randomised controlled trials. Lancet Respir Med. 2014;2:472-486.

10. ANORO ELLIPTA [prescribing information]. Available from: http:// www.accessdata.fda.gov/drugsatfda_docs/label/2013/203975s000lbl. pdf. Accessed April 16, 2014

11. Bateman ED, Ferguson GT, Barnes N, et al. Dual bronchodilation with QVA149 versus single bronchodilator therapy: the SHINE study. Eur Respir J. 2013;42:1484-1494.

12. Dahl R, Jadayel D, Alagappan VK, Chen H, Banerji D. Efficacy and safety of QVA149 compared to the concurrent administration of its monocomponents indacaterol and glycopyrronium: the BEACON study. Int J Chron Obstruct Pulmon Dis. 2013;8:501-508.

13. Dahl R, Chapman KR, Rudolf M, et al. Safety and efficacy of dual bronchodilation with QVA149 in COPD patients: the ENLIGHTEN study. Respir Med. 2013;107:1558-1567.

14. Mahler DA, Decramer M, D’Urzo A, et al. Dual bronchodilation with QVA149 reduces patient-reported dyspnoea in COPD: BLAZE study. Eur Respir J. 2013;43(6):1599-1609.

15. Vogelmeier CF, Bateman ED, Pallante J, et al. Efficacy and safety of once-daily QVA149 compared with twice-daily salmeterol-fluticasone in patients with chronic obstructive pulmonary disease (ILLUMINATE): a randomised, double-blind, parallel group study. Lancet Respir Med. 2013;1:51-60.

16. Wedzicha JA, Decramer M, Ficker JH, et al. Analysis of chronic obstructive pulmonary disease exacerbations with the dual bronchodilator QVA149 compared with glycopyrronium and tiotropium (SPARK): a randomised, double-blind, parallel-group study. Lancet Respir Med. 2013;1:199-209.

17. Mahler DA, D'Urzo A, Bateman ED, et al. Concurrent use of indacaterol plus tiotropium in patients with COPD provides superior bronchodilation compared with tiotropium alone: a randomised, double-blind comparison. Thorax. 2012;67:781-788.

18. Tashkin DP, Pearle J, Iezzoni D, Varghese ST. Formoterol and tiotropium compared with tiotropium alone for treatment of COPD. COPD. 2009;6:17-25.

19. Vogelmeier C, Kardos P, Harari S, Gans SJ, Stenglein S, Thirlwell J. Formoterol mono- and combination therapy with tiotropium in patients with COPD: a 6-month study. Respir Med. 2008;102:1511-1520.

20. Aaron SD, Vandemheen KL, Fergusson D, et al; Canadian Thoracic Society/Canadian Respiratory Clinical Research Consortium. Tiotropium in combination with placebo, salmeterol, or fluticasone-salmeterol for treatment of chronic obstructive pulmonary disease: a randomized trial. Ann Intern Med. 2007;146:545-555.

21. Cazzola M, Andò F, Santus P, et al. A pilot study to assess the effects of combining fluticasone propionate/salmeterol and tiotropium on the airflow obstruction of patients with severe-to-very severe COPD. Pulm Pharmacol Ther. 2007;20:556-561.

22. Ultibro Breezhaler (QVA149) approved in Europe; 2013. Available from: http://www.vectura.com/media/press-releases/2013/23-sep-2013. aspx. Accessed April 16, 2014.

23. U.S. Food and Drug Administration (FDA). FDA news release. FDA approves Anoro Ellipta to treat chronic obstructive pulmonary disease; 2013. Available from: http://www.fda.gov/newsevents/newsroom/pressannouncements/ucm379057.htm. 2013. Accessed April 16, 2014.
24. Dossier zur Nutzenbewertung gemäß § 35a SGB VIQWiG. Dokumentvorlage, Version vom 18.04.2013. Available from: https://www.g-ba. de/downloads/17-98-3528/2013-04-18_Anl2_6_Modul4.pdf. Accessed April 16, 2014.

25. Jansen JP, Naci H. Is network meta-analysis as valid as standard pairwise meta-analysis? It all depends on the distribution of effect modifiers. BMC Med. 2013;11:159.

26. Cope S, Zhang J, Saletan S, Smiechowski B, Jansen JP, Schmid P. A process for assessing the feasibility of a network meta-analysis: a case study of everolimus in combination with hormonal therapy versus chemotherapy for advanced breast cancer. BMC Med. 2014;12:93

27. Dias S, Sutton AJ, Ades AE, Welton NJ. Evidence synthesis for decision making 2: a generalized linear modeling framework for pairwise and network meta-analysis of randomized controlled trials. Med Decis Making. 2013;33:607-617.

28. Maleki-Yazdi MR, Kaelin T, Richard N, Zvarich M, Church A. Efficacy and safety of umeclidinium/vilanterol $62.5 / 25 \mathrm{mcg}$ and tiotropium $18 \mathrm{mcg}$ in chronic obstructive pulmonary disease: results of a 24-week, randomized, controlled trial. Respir Med. 2014;108: $1752-1760$

29. Donohue JF, van Noord JA, Bateman ED, et al. A 6-month, placebocontrolled study comparing lung function and health status changes in COPD patients treated with tiotropium or salmeterol. Chest. 2002; 122:47-55.

30. Huisman E, Cockle S, Punekar Y. Comparative assessment of umeclidinium/vilanterol (UMEC/VI) combination therapy among symptomatic COPD patients. ERJ. 2014;44(58):894.

31. Kew KM, Dias S, Cates CJ. Long-acting inhaled therapy (beta-agonists, anticholinergics and steroids) for COPD: a network meta-analysis. Cochrane Database Syst Rev. 2014;3:CD010844.

32. Cope S, Donohue JF, Jansen JP, et al. Comparative efficacy of longacting bronchodilators for COPD - a network meta-analysis. Respir Res. 2013;14:100.

33. Rajnoveanu RM, Antoniu S, Ulmeanu R. Combined long-acting bronchodilator single therapy for COPD. Expert Opin Pharmacother. 2014;15:139-142.

34. Tashkin DP, Ferguson GT. Combination bronchodilator therapy in the management of chronic obstructive pulmonary disease. Respir Res. $2013 ; 14: 49$

35. Karabis A, Lindner L, Mocarski M, Huisman E, Greening A. Comparative efficacy of aclidinium versus glycopyrronium and tiotropium, as maintenance treatment of moderate to severe COPD patients: a systematic review and network meta-analysis. Int J Chron Obstruct Pulmon Dis. 2013;8:405-423.

36. Chan CK, Maltais F, Sigouin C, Haddon JM, Ford GT. A randomized controlled trial to assess the efficacy of tiotropium in Canadian patients with chronic obstructive pulmonary disease. Can Respir J. 2007;14:465-472.

37. Tonnel AB, Perez T, Grosbois JM, Verkindre C, Bravo ML, Brun M. Effect of tiotropium on health-related quality of life as a primary efficacy endpoint in COPD. Int J Chron Obstruct Pulmon Dis. 2008; 3:301-310.

38. Tashkin DP, Celli B, Senn S, et al; UPLIFT Study Investigators. A 4-year trial of tiotropium in chronic obstructive pulmonary disease. N Engl J Med. 2008;359:1543-1554.

39. Celli B, Decramer M, Kesten S, Liu D, Mehra S, Tashkin DP. Mortality in the 4-year trial of tiotropium (UPLIFT) in patients with chronic obstructive pulmonary disease. Am J Respir Crit Care Med. 2009;180:948-955.

40. Niewoehner DE, Rice K, Cote C, et al. Prevention of exacerbations of chronic obstructive pulmonary disease with tiotropium, a once-daily inhaled anticholinergic bronchodilator: a randomized trial. Ann Intern Med. 2005;143:317-326.

41. Brusasco V, Hodder R, Miravitlles M, Korducki L, Towse L, Kesten S. Health outcomes following treatment for six months with once daily tiotropium compared with twice daily salmeterol in patients with COPD. Thorax. 2003;58:399-404. 
42. Casaburi R, Mahler DA, Jones PW, et al. A long-term evaluation of once-daily inhaled tiotropium in chronic obstructive pulmonary disease. Eur Respir J. 2002;19:217-224.

43. Donohue JF, Fogarty C, Lötvall J, et al; Inhance Study Investigators. Once-daily bronchodilators for chronic obstructive pulmonary disease: indacaterol versus tiotropium. Am J Respir Crit Care Med. 2010;182:155-162.

44. Kerwin E, Hébert J, Gallagher N, et al. Efficacy and safety of NVA237 versus placebo and tiotropium in patients with COPD: the GLOW2 study. Eur Respir J. 2012;40:1106-1114.

45. Verkindre C, Bart F, Aguilaniu B, et al. The effect of tiotropium on hyperinflation and exercise capacity in chronic obstructive pulmonary disease. Respiration. 2006;73:420-427.

46. Casaburi R, Briggs DD Jr, Donohue JF, Serby CW, Menjoge SS, Witek TJ Jr. The spirometric efficacy of once-daily dosing with tiotropium in stable COPD: a 13-week multicenter trial. The US Tiotropium Study Group. Chest. 2000;118:1294-1302.
47. Covelli H, Bhattacharya S, Cassino C, Conoscenti C, Kesten S. Absence of electrocardiographic findings and improved function with once-daily tiotropium in patients with chronic obstructive pulmonary disease. Pharmacotherapy. 2005;25:1708-1718.

48. Garcia RF. A randomised, double-blind, placebo-controlled, 12 weeks trial to evaluate the effect of Tiotropium Inhalation Capsules on the magnitude of exercise, measured using an accelerometer, in patients with Chronic Obstructive Pulmonary Disease (COPD). Boehringer Ingelheim Trial Results 2007. Available from: http://trials.boehringeringelheim.com/content/dam/internet/opu/clinicaltrial/com_EN/ results/205/205.269.pdf. Accessed April 16, 2014.

49. Moita J, Bárbara C, Cardoso J, et al. Tiotropium improves FEV1 in patients with COPD irrespective of smoking status. Pulm Pharmacol Ther. 2008;21:146-151.

\section{Publish your work in this journal}

The International Journal of COPD is an international, peer-reviewed journal of therapeutics and pharmacology focusing on concise rapid reporting of clinical studies and reviews in COPD. Special focus is given to the pathophysiological processes underlying the disease, intervention programs, patient focused education, and self management protocols.

\section{Dovepress}

This journal is indexed on PubMed Central, MedLine and CAS. The manuscript management system is completely online and includes a very quick and fair peer-review system, which is all easy to use. Visit http://www.dovepress.com/testimonials.php to read real quotes from published authors.

Submit your manuscript here: http://www.dovepress.com/international-journal-of-chronic-obstructive-pulmonary-disease-journal 